\title{
5
}

\section{Hydraulic Modeling of Deep Tunnel Provides Cost Savings}

\author{
Taymour El-Hosseiny, Karen Reinhart and M. P. Cherian
}

In 2005, the City of Columbus, Ohio submitted a plan to the Ohio Environmental Protection Agency (EPA) to manage its wet weather flow which includes a list of proposed improvements to eliminate or mitigate combined sewer overflows (CSOs). Critical components of the plan are the Olentangy-Scioto interceptor sewer (OSIS) augmentation relief sewer (OARS), the construction of $\mathrm{CSO}$ high rate treatment, and a $10 \mathrm{MG}$ storage facility to meet the desired level of control of zero overflow in a typical year. The total estimated cost of these three components in 2005 dollars was \$396 million.

During the design phases of OARS, the city expressed interest in increasing the level of control of the downtown CSOs. A value engineering team favoured a deep tunnel option for OARS. A hydraulic SWMM model was developed to optimize the size of OARS through examining the capability of the collection system to meet the higher level of control of the downtown CSOs.

Modeling showed there was flexibility to allow the implementation of different methods of flow control in the collection system by adjusting gate settings, the operational rates of pump stations, and different tunnel sizes and numbers of shafts, all of which was reflected in cost savings of $\$ 103$ million. The modeling also identified constraints of the wastewater treatment plant (WWTP) capacities and limitations of the existing collection system.

\subsection{Introduction}

Under a consent order by the Ohio EPA, the City of Columbus is obligated to develop a combined sewer overflow long term control plan (CSO LTCP) to mitigate overflow from its combined sewer systems (CSS). The city's CSS is

El-Hosseiny, T., K. Reinhart, and M.P. Cherian. 2012. "Hydraulic Modeling of Deep Tunnel Provides Cost Savings." Journal of Water Management Modeling R245-05. doi: 10.14796/JWMM.R245-05.

(C) CHI 2012 www.chijournal.org ISSN: 2292-6062 (Formerly in On Modeling Urban Water Systems. ISBN: 978-0-9808853-7-8) 
concentrated in an older service area which serves the downtown and surrounding areas. Figure 5.1 (opposite) illustrates tributary areas to the CSS where OSIS is the main trunk sewer to convey the combined flow.

OSIS was designed in 1932 to convey all dry weather flow and allow a limited wet weather flow to the WWTPs. There are currently 30 permitted CSO locations within the Columbus CSS as shown in Figure 5.1. The estimated annual CSO volume from these locations is $1320 \mathrm{MG}\left(5000000 \mathrm{~m}^{3}\right)$ using a typical year rainfall for the central Ohio area. The typical year as defined herein represents the average precipitation year expected in central Ohio, based on a statistical analysis of approximately 60 years of hourly rainfall data from Port Columbus International Airport (one of the city's airports). The largest contributing CSO is from a single site located at the Whittier Street storm tanks (WSST). On average, this site activates 38 times annually and discharges approximately $1200 \mathrm{MG} / \mathrm{y}\left(4500000 \mathrm{~m}^{3}\right)$. Figure 5.2 illustrates annual overflow volume from WSST data using data recorded by flow meters.

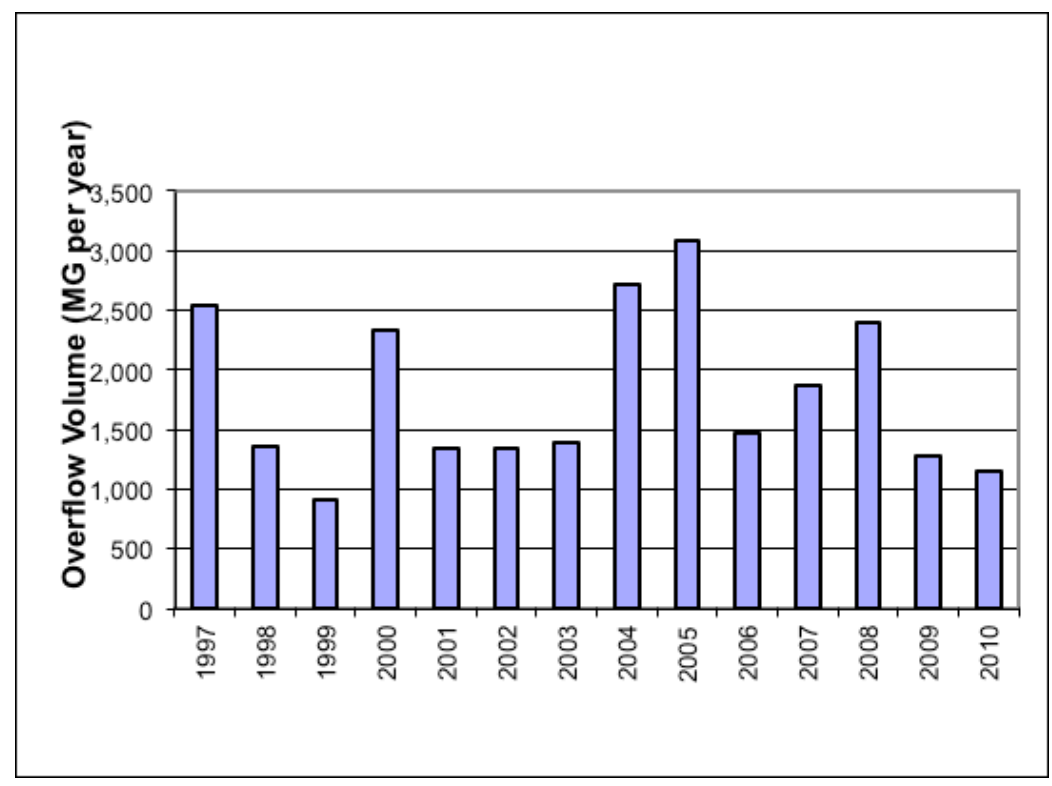

Figure 5.2 Yearly overflow volume at WSST, Columbus, Ohio.

The city is subject to another consent order to develop a system evaluation and capacity assurance plan aimed at resolving deficiencies in key components of the separate sanitary sewer system and eliminating known designed sanitary reliefs. 


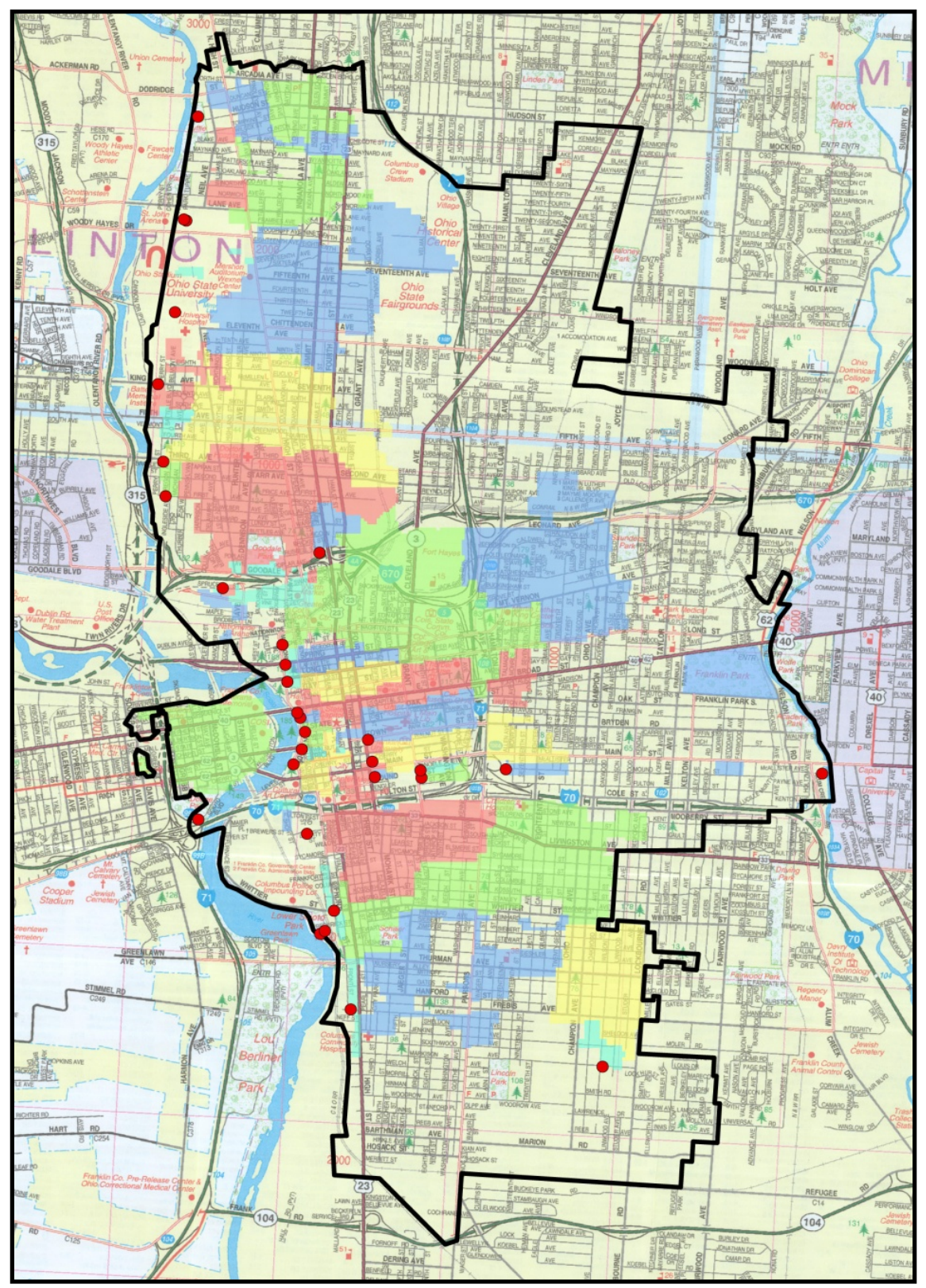

Figure 5.1 Combined sewer area and locations of CSO regulators. 
After consideration of how to balance these requirements, and the interaction between the separate sewer system and the combined sewer system, the city decided to develop a wet weather management plan (WWMP) to quantify identified problems collectively and provide comprehensive alternatives.

\subsection{The Wet Weather Management Plan}

Figure 5.3 is a schematic of the recommended facilities to eliminate or mitigate CSOs for Columbus. These are explained in the following.

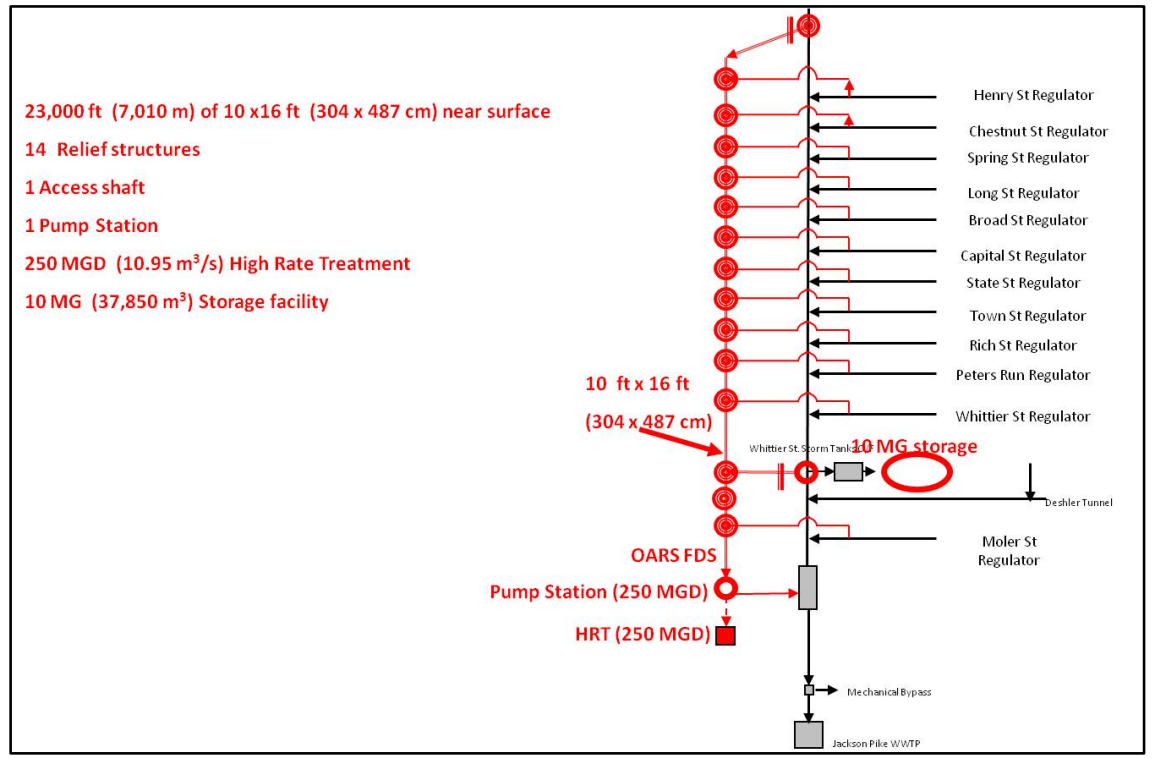

Figure 5.3 Schematic of the proposed facilities by the WWMP.

The WWMP for Columbus recommends the use of a combination of technologies to get a $99.4 \%$ capture of yearly wet weather flow and a maximum of four CSO events annually. The proposed technologies for the CSO LTCP are:

- OARS, which is intended to intercept overflow at the outlet of the identified CSOs, that would be a near surface box $10 \mathrm{ft} \times 16$ $\mathrm{ft}(3.05 \mathrm{~m} \mathrm{x} 4.88 \mathrm{~m})$ which will discharge into the WWTP; and

- excess flow above the capacity of OARS will receive partial treatment via high rate treatment (HRT).

The above technologies are supported by:

- $\quad$ increasing capture by fully opening regulator gates to prevent potential flow restriction; 
increasing system storage by raising current weirs at the regulators without affecting sewer services to current or future customers (i.e. no water-in-basements);

- source control using inflow redirection of storm sewers that discharge into the current combined sewer system; and storage tank to store peak flow above the capacity of the proposed OARS.

This chapter focuses on the proposed OARS, HRT and the storage tanks.

\subsection{Objectives}

A hydraulic model was developed during the design phase of OARS using the Stormwater Management Model (SWMM 4.4h) to optimize the size of OARS and all connecting sewers. The performance of the collection system was evaluated to ensure the desired level of control. In summary, the objectives were:

optimize the sizes and elevations for OARS and ancillary structures to achieve anticipated levels of control;

estimate overflow volume, frequency and flow rate at the identified CSO locations before and after the incorporation of proposed improvements; and

examine the current operation plan to manage flow between the Jackson Pike WWTP and Southerly WWTP, and develop strategies to optimize the use of the collection system.

\subsection{Value Engineering}

A value engineering team evaluated the near surface facility proposed by the WWMP before detailed design began. The team evaluated three primary construction methods for the OARS: near surface conduit, deep tunnel and shallow tunnel. An alternative evaluation matrix was developed with input provided by the city regarding capital costs, right of way acquisition, constructability, ease of operation and economic impacts. The results of the evaluation favoured the deep tunnel and recommended the use of the modeling analysis to optimize the size of the proposed sewer tunnel and all ancillary structures.

\subsection{System Characterization}

The population forecasts and tributary areas were used as the basis for evaluating the function and size of OARS for both current and future flow conditions. 
The Mid-Ohio Regional Planning Commission (MORPC) forecasts population and employment estimates for the central Ohio area. MORPC data was available for the years 2000 and 2030 (Mid-Ohio Regional Planning Commission, 2011). The development of the sewersheds was not allowed to exceed $80 \%$ of the land considered to be developable as agreed with the city. The Columbus area tributary to the collection system was divided into five primary areas as follows:

1. Combined sewer area tributary to OSIS which covers the collection system between the Hudson Street regulator to the WSST control house. The regulators in the combined sewer area divert excess combined flow during wet weather conditions to the Olentangy river, the Scioto river or to a storm pipe;

2. Separate sanitary sewer area tributary to OSIS which includes the separate sanitary sewer portion of the collection system that discharges into OSIS, upstream of the combined system;

3. Separate sanitary sewer area tributary to the Jackson Pike WWTP which includes sewersheds tributary to the Jackson Pike WWTP downstream of the combined sewer area (downstream of the WSST);

4. Separate sanitary sewer area tributary to the Interconnector sanitary sewer which includes sewersheds tributary to the Southerly WWTP, downstream of the Jackson Pike WWTP. This subarea covers mainly the Grove City sewershed basin, the Big Run sanitary trunk sewer and the Williams Road sewershed; and

5. The Big Walnut Creek tributary area includes all sewersheds that are within the east side of the Columbus collection system and are directly tributary to the Southerly WWTP through the Big Walnut sanitary outfall sewer and the Big Walnut Augmentation Rickenbacker Interceptor.

Tables 5.1 and 5.2 list tributary areas and projected population at critical dates to meet the requirements of the consent orders.

Table 5.1 Population projections.

\begin{tabular}{clcc}
\hline Area number & \multicolumn{1}{c}{ Tributary Sub-Area } & $\begin{array}{c}2030 \\
\text { (capita) }\end{array}$ & $\begin{array}{c}\text { Build-Out } \\
\text { (capita) }\end{array}$ \\
\hline 1 & OSIS Combined & 163700 & 167200 \\
2 & OSIS Separate & 217600 & 229800 \\
3 & Jackson Pike & 563600 & 802900 \\
4 & Interconnector Sanitary Sewer & 95200 & 304600 \\
5 & Big Walnut Creek & 865400 & 1780400 \\
& $\quad$ TOTAL & 1905500 & 3284900 \\
\hline
\end{tabular}


Table 5.2 Tributary area projections.

\begin{tabular}{clcc}
\hline Area \# & \multicolumn{1}{c}{ Tributary Sub-Area } & $\begin{array}{c}2030 \\
\text { (acres) }\end{array}$ & $\begin{array}{c}\text { Build-Out } \\
\text { (acres) }\end{array}$ \\
\hline 1 & OSIS Combined & 10500 & 10700 \\
2 & OSIS Separate & 18700 & 19700 \\
3 & Jackson Pike & 47700 & 67600 \\
4 & Interconnector Sanitary Sewer & 8800 & 26300 \\
5 & Big Walnut Creek & 78900 & 155200 \\
& TOTAL & 164600 & 279500 \\
\hline
\end{tabular}

\subsection{Modified Alternative}

Numerous model runs were executed to optimize the size and operation of OARS and its ancillary structures. The city expressed interest in increasing the level of control for all downtown CSOs to be above the requirements of the consent order. The following are the predefined criteria to be achieved after the completion of all proposed improvements (in the year 2025):

typical year rainfall level of control:

- significant reduction in CSO volume;

- eliminate CSO at WSST;

- maximum of four CSO events annually at the OARS diversion structure;

o no CSO from all existing regulators;

2 y flow level of control:

- no CSO from downtown regulators; and

$5 \mathrm{y}$ and $10 \mathrm{y}$ flow level of control:

- possible elimination of CSO from downtown regulators.

Critical model parameters were examined using the typical year rainfall, $2 \mathrm{y}$, $5 \mathrm{y}$ and $10 \mathrm{y}$ levels of control, for the buildout conditions. The following items were explored to optimize parameters which represent critical components of the proposed OARS:

determine weir height in the relief structures between OSIS and the proposed OARS to maximize the diversion of wet weather flow;

minimize the number of diversion shafts to reduce the cost of the project;

optimize the size of OARS to achieve the anticipated level of control;

- eliminate unnecessary relief connections due to constructability issues and economic impacts on current businesses; 
- investigate the possibility and need to eliminate the proposed HRT; and

- improve model accuracy by improving model stability.

Using the above analysis and results from the hydraulic model, OARS was modified from its original proposal. Figure 5.4 illustrates the conceptual layout of OARS in 2025. Table 5.3 illustrates a comparison between the proposed components of OARS from the WWMP and the final design.

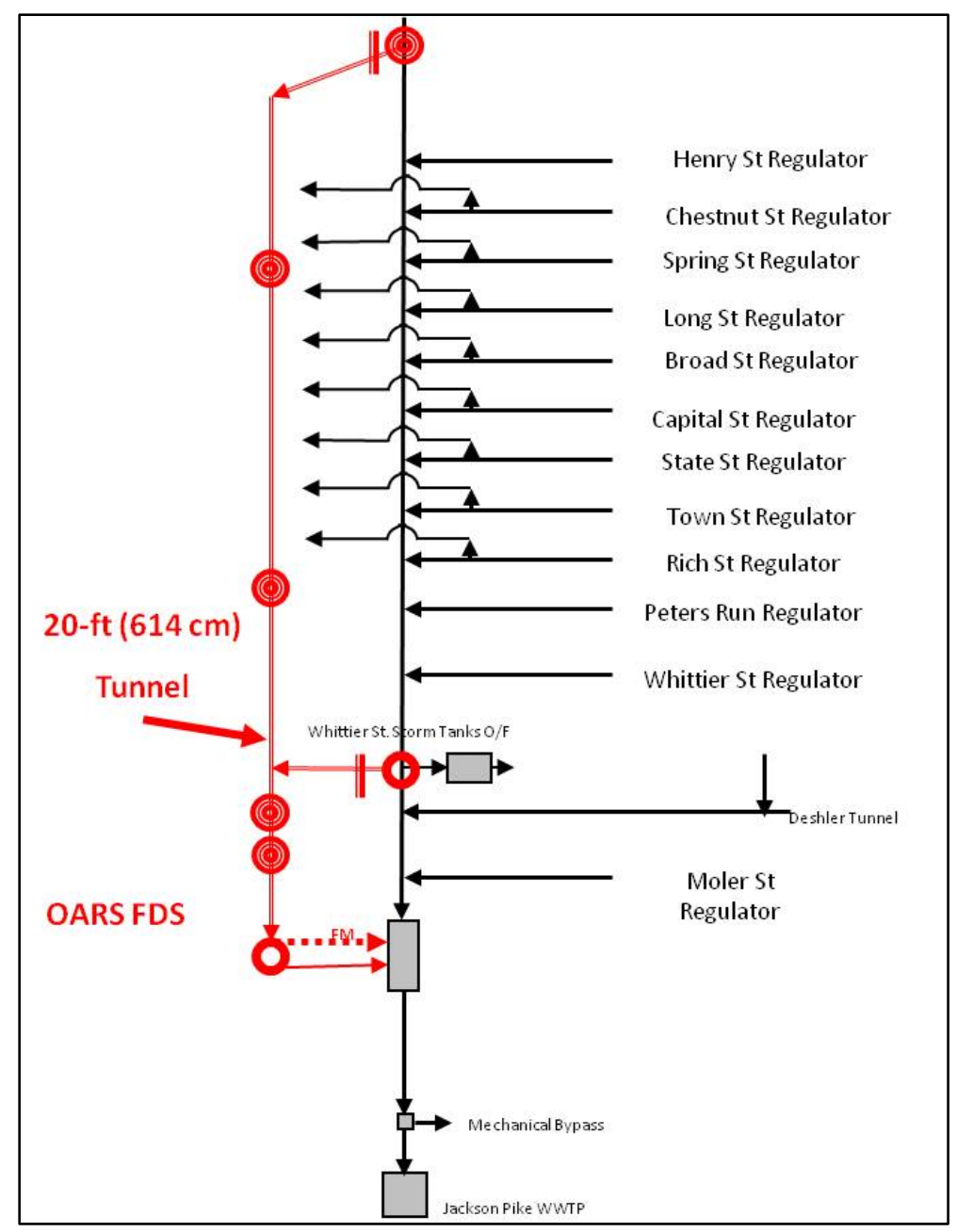

Figure 5.4 Schematic of OARS after the modeling optimization. 
Table 5.3 Comparison between OARS components for the WWMP and the final design.

\begin{tabular}{lcc}
\hline \multicolumn{1}{c}{ OARS Component } & WWMP & Final Design \\
\hline Construction Method & Near Surface & Deep tunnel \\
Size & $10 \mathrm{ft} \times 16 \mathrm{ft}$ box & $20 \mathrm{ft} \mathrm{diameter}$ \\
Relief structures & 13 relief structures & $\begin{array}{c}3 \text { relief structures and 3 } \\
\text { overflow connections }\end{array}$ \\
Number of shafts & 16 near surface shafts & 6 deep shafts \\
Off line storage & $10 \mathrm{MG}$ tank & None \\
High rate treatment & $250 \mathrm{MGD}$ facility & None \\
\hline
\end{tabular}

OARS was modeled as a $20 \mathrm{ft}(6.1 \mathrm{~m})$ diameter deep tunnel, collecting combined flow via three relief structures from OSIS. OARS stores and conveys the flow to the OARS flow diversion structure (FDS). The received flow at OARS FDS would be conveyed to the Jackson Pike WWTP which has a capacity of $150 \mathrm{MGD}\left(6.57 \mathrm{~m}^{3} / \mathrm{s}\right)$. Excess flows above the capacity of the Jackson Pike WWTP would be diverted to the Southerly WWTP which has a capacity of $330 \mathrm{MGD}\left(14.45 \mathrm{~m}^{3} / \mathrm{s}\right)$. If both WWTPs were to reach their capacities, overflow from OARS FDS would be allowed.

Due to construction risks in the downtown area, it is the desire of the city to have a minium number of shafts. For example, it was initally proposed to construct a relief shaft at the Chestnut Street regulator area and the hydraulic analysis was used to determine alternatives to eliminate the need for that shaft. The following optimization techniques were employed:

increase capture to OSIS at the Chestnut Street regulator by removing the sluice gate located between the regulator room and the intercepting connection;

- $\quad$ increase capture to OSIS at the Henry Street regulator by removing the sluice gate located inside the regulator room upstream of the intercepting connection to OSIS ;

- use real time control (RTC) to divert the entire discharge of OSIS into OARS using the Henry Street shaft;

- $\quad$ use RTC to divert flow from OSIS to OARS during high flow events;

- $\quad$ use RTC to activate the WSST emergency bypass gates when the water level inside the Spring Street and Henry Street regulators reached certain elevations; and

- control or reduce tributary flow from the existing 108 in. $(2.70 \mathrm{~m})$ Nationwide storm sewer to the Chestnut Street regulator.

It is concluded that three new relief structures in the vicinity of existing regulators should be proposed to redirect wet weather flow to OARS. These relief structures consist of diversion weirs to relieve flow from OSIS to OARS. In 
addition, new sewers are proposed to connect the overflow weirs at the nearby regulators to OARS. Where possible, the overflow from the relief structure and the connector sewer will be combined and directed towards an approach channel and a vertical shaft that will drop the flow into the OARS tunnel. Table 5.4 lists the three relief structures and proposed sizes for each diversion weir on OSIS as specified in the hydraulic model.

Table 5.4 Model assumptions for the relief structures between OSIS and OARS.

\begin{tabular}{lcccc}
\hline \multicolumn{1}{c}{ Relief Structure } & $\begin{array}{c}\text { OSIS Diver- } \\
\text { sion Weir } \\
\text { Length (ft) }\end{array}$ & $\begin{array}{c}\text { OSIS Diver- } \\
\text { sion Weir } \\
\text { Height (ft) }\end{array}$ & $\begin{array}{c}\text { Approach } \\
\text { Channel } \\
\text { Dimensions (ft) }\end{array}$ & $\begin{array}{c}\text { Tunnel Shaft } \\
\text { Diameter (ft) }\end{array}$ \\
\hline $\begin{array}{l}\text { Shaft \#8 } \\
\text { OSIS Relief Structure } \\
\text { (Henry St. Regulator) }\end{array}$ & 20 & 3 & $12.0 \times 25$ & 16 \\
$\begin{array}{l}\text { Shaft \#6 } \\
\begin{array}{l}\text { OSIS Relief Structure } \\
\text { (Short St.) }\end{array}\end{array}$ & 20 & 4 & $12 \times 28.5$ & 16 \\
$\begin{array}{l}\text { Shaft \#5 } \\
\text { OSIS Relief Structure } \\
\text { (WSST) }\end{array}$ & 20 & 4 & $12 \times 31.0$ & 16 \\
\hline
\end{tabular}

OARS FDS is located at the downstream end of the OARS tunnel. It directs the combined sewer flow from OARS to OSIS FDS by either pumping or gravity flow. The associated model components for OARS FDS are as follows.

A $60 \mathrm{MGD}\left(2.63 \mathrm{~m}^{3} / \mathrm{s}\right)$ pump station is used to dewater the tunnel with discharge into OSIS FDS. The pump activates as soon as water builds up to a depth of $3 \mathrm{ft}(91.5 \mathrm{~cm})$ (elevation 533.60; all elevations in this chapter are referenced to the National Geodetic Vertical Datum 1929) in the tunnel near OARS FDS to capture the first flush of combined sewer flow. It shuts off when the water level approaches the invert of the gravity pipe between OARS FDS and OSIS FDS. The pumps begin to dewater the tunnel when the water level drops below the gravity pipe invert (elevation 686.60).

A $10 \mathrm{ft}(3.05 \mathrm{~m})$ diameter gravity pipe conveys flow from OARS FDS to OSIS FDS. The invert of the pipe is at elevation 686.60, which is set above the peak dry weather flow elevation expected in OSIS FDS. A sluice gate located in OARS FDS is used to control the flow through the $10 \mathrm{ft}$ (3.05 m) pipe into OSIS FDS. The gate will shut when the water level reaches critical stages at the WWTPs. In addition, a flap gate is present to prevent sanitary backflow into OARS FDS.

A $102 \mathrm{ft}(31.09 \mathrm{~m})$ long overflow weir conveys flow to a channel which will discharge to the Scioto river via four $8 \mathrm{ft}(2.44 \mathrm{~m})$ diameter pipes. The overflow weir crest will be set at elevation 700.00 . 


\subsection{Estimated Costs}

Costs for installing the proposed components of OARS were evaluated considering the market condition at the time bids were submitted, and the projected construction duration and cost escalations per year.

Table 5.5 lists estimated costs of identified facilities by the WWMP and their probable cost after implementing the modeling analysis to optimize their functions.

Table 5.5 Comparison between the estimated costs of identified facilities for the Columbus CSO LTCP.

\begin{tabular}{lcc}
\hline \multicolumn{1}{c}{ Component } & WWMP (\$million) & Final Design (\$million) \\
\hline OSIS Augmented Relief Sewer (OARS) & 260 & 320 \\
Offline Storage & 76 & 0 \\
High rate treatment & 125 & 0 \\
Connections & 5 & 30 \\
Total & 466 & 350 \\
\hline
\end{tabular}

As illustrated in Table 5.5, the modeling analysis optimized OARS to achieve anticipated level of control as required by the consent order and saved a of $\$ 116$ million compared to the initial estimated costs.

\subsection{Conclusions}

The computer model was employed to optimize the OARS tunnel which is reflected in cost savings as follows:

ensure the OARS tunnel would eliminate the need for the proposed $10 \mathrm{MG}\left(37854 \mathrm{~m}^{3}\right)$ storage tank;

- $\quad$ size OARS to eliminate the need for high rate treatment which represents a cost savings of $\$ 103$ million;

identify the optimum locations and elevations to intercept flow from OSIS to minimize the required number of tunnel shafts (these structures are designed to relieve OSIS during wet weather by diverting flow over a fixed crest weir; when flow levels exceed the weir elevation, flow will be directed into OARS); and

- eliminate the need for collector sewers from each CSO due to the lowered hydraulic grade line in OSIS.

After the construction of OARS (2014), the model estimates that the total CSO volume will be $50 \mathrm{MG}\left(189000 \mathrm{~m}^{3}\right)$, which is a reduction of $96 \%$ from the 2005 volume, using the typical year rainfall for central Ohio. The modeling revealed the opportunity to implement different methods to appropriately 
control flow in the collection system by adjusting gate settings, the operational rates of pump stations and different tunnel sizes. It also identified constraints of the WWTP capacities and the limitations of the existing collection system.

\section{Reference}

Mid-Ohio Regional Planning Commission. 2011. Population Estimates. Available through http://www.morpc.org/index.asp. 